\title{
Implementation of an Optimal Energy Management within Islanded Microgrid
}

\author{
M. Marzband ${ }^{1}$, A. Sumper ${ }^{1,2}$ \\ ${ }^{1}$ Electric Power Grids Area \\ Catalonia Institute for Energy Research \\ Jardins de les Dones de Negre, $12^{\mathrm{a}} \mathrm{Pl}, 08930$ Barcelona (Spain) \\ Phone:+34 933562 615, e-mail: mmarzband@irec.cat \\ ${ }^{2}$ Centre d'Innovació Tecnològica en Convertidors Estàtics i Accionaments (CITCEA-UPC), Universitat Politècnica de \\ Catalunya (UPC), C. Comte d'Urgell 187, Pl. 2. 08036 Barcelona, Spain \\ Phone:+34 9340167 27, e-mail: andreas.sumper@upc.edu
}

\begin{abstract}
This paper proposes an optimal Energy Management System (EMS) based on Mixed Integer Linear Programming (MILP) optimization technique for an islanded Microgrid (MG). A local energy market (LEM) platform is employed which attempts to obtain the best electricity market price and to maximize the utilization of existing distributed energy resources. Besides, a single side auction market structure is used for the LEM which takes the offer prices from all microsources to calculate market clearing price. Simulation and experimental results from the proposed method over a real MG are compared with those from a Modified Conventional EMS (MCEMS). The proposed algorithm is flexible, extendable and too fast to be utilized for different MG structures with various capacities. The results demonstrate the effectiveness of the proposed method to solve the optimal operation problem in an isolated $\mathrm{MG}$ with $25 \%$ reduction in the cost of operation.
\end{abstract}

\section{Key words}

Energy Management System, Local Energy Market, Mixed Integer Linear Programming

\section{Notations}

$\pi^{\mathrm{A}}$ : the supply bids by $\mathrm{A}(€ / \mathrm{kWh})$

$\mathrm{A} €\{\mathrm{WT}, \mathrm{PV}, \mathrm{ES}-$, and MT $\}$

$\lambda_{t}^{\mathrm{MCP}}, \lambda_{\mathrm{t}}^{\prime \mathrm{MCP}}$ : Market Clearing Price (MCP) at each time $\mathrm{t}$ in MCEMS and EMS-MILP, respectively $(€ / \mathrm{kWh})$

$\mathrm{P}_{t}^{\mathrm{B}}, \mathrm{P}_{\mathrm{t}}^{\prime} \mathrm{B}$ : available power of $\mathrm{B}$ in MCEMS and EMSMILP, respectively $(\mathrm{kW})$

$\mathrm{B} €\{\mathrm{~A}, \mathrm{ES}+, \mathrm{EWH}, \mathrm{TCP}$, and EGP $\}$

$\mathrm{P}_{\mathrm{t}}^{\mathrm{n}}$ : uncontrollable load demand at each time step $(\mathrm{kW})$

SOC $_{\mathrm{t}}$ : State of charge at time $\mathrm{t}(\%)$

\section{Introduction}

MG architectures are designed to significantly improve the efficiency of energy production and delivery for the load customers and to maintain the balance between power generation and load demand mostly at the distribution level. It is also desired to obtain more stable electrical infrastructure with measurable reduction in environmental emissions and increased power quality through MGs [1, 2 and 3]. In order to achieve this goal, the energy management of the generation and storage assets within the MG is required at the distribution level to optimize the energy utilization and to enhance energy sustainability [4].

As mentioned in [5], the main objective of the EMS is to make decisions regarding the best use of the electric power generation resources and storage devices in the MG. Such decisions will be based on the energy requirements of the local customers, minimizing the Cost of Energy (COE) production and the amount of the Unmet Power (UP) which is considered as penalty cost, utilizing the Excess Generated Power (EGP) in the storage devices and/or useful dump load such as Electrical Water Heat (EWH), cost of fuel, and other technical/economical constrains.

Various configurations for the EMS with different optimization methods and MG structures are presented in the literature. In some studies, the proposed EMS is implemented without optimization [3]. In many other researches, the EMS with optimization are addressed in order to achieve optimal scheduling $[6,7]$ and operating strategy [8-15].

In [7, 16 and 17] cost minimization in the EMS is considered using different optimization techniques. The formulated objective function allows for autonomous or grid connected decision-making to determine hour by hour optimal dispatch of generators subject to system constraints including market parameters. In these studies, Artificial Neural Networks (ANN) and Mesh Adaptive Direct Search (MADS) are adopted to make decisions and determine hour-by-hour dispatch of generators with the final goal of minimizing the global energy costs.

The economic concepts of the EMS in the MG market and the development of strategies for achieving such 
benefits are reported in [17-22]. Heuristic methods such as GA and Partial Swarm Optimization (PSO) are mainly utilized in these researches.

This paper attempts to address different objectives such as optimal scheduling and minimizing overall $\mathrm{COE}$ based on several market criteria in a LEM through an efficient EMS.

\section{Problem formulation}

\subsection{MINLP method}

In this study, mixed-integer nonlinear programming (MINLP) is utilized in the optimization unit to solve the MG optimization problem [23]. MINLP refers to mathematical programming with continuous and discrete variables and nonlinearities in the objective function and constraints [23]. The use of MINLP is a natural approach of formulating problems where it is necessary to simultaneously optimize the system structure (discrete) and parameters (continuous). The general form of a MINLP is as follows [23]:

$$
\operatorname{Min} \mathbf{f}(\mathbf{x}, \mathbf{y})^{(1)}
$$

subject to

$$
\begin{array}{r}
\mathbf{g}(\mathbf{x}, \mathbf{y})=\mathbf{g}^{\prime}(\mathbf{x}, \mathbf{y})^{(2)} \\
\mathbf{h}(\mathbf{x}, \mathbf{y}) \leq \mathbf{h}^{\prime}(\mathbf{x}, \mathbf{y})^{(3)} \\
\mathbf{x} \in \mathbf{X}(4) \\
\mathbf{y} \in \mathbf{Y}(5)
\end{array}
$$

where $\mathbf{f}(\mathbf{x}, \mathbf{y})$ is a linear/nonlinear objective function and $\mathbf{g}(\mathbf{x}, \mathbf{y})$ is a linear/nonlinear constraint function; $\mathbf{x}, \mathbf{y}$ are the decision variables, where $\mathbf{y}$ is required to be integer valued (e.g., the MG characteristic matrix); and $\mathbf{X}$ and $\mathbf{Y}$ are bounding-box-type restrictions on the variables. More detail about MINLP is given in [23]. The General Algebraic Mathematical System (GAMS) package with "CONOPT" solver is used in this study to implement MINLP technique [23].

\subsection{Formulation of the MILP-based EMS}

In order to verify the effectiveness of the proposed EMS, a stand-alone MG including Wind Turbine (WT)Photovoltaic (PV)-Microturbine (MT) and Energy Storage (ES) is developed with real data. In this paper, an optimal EMS, which is called EMS-MILP, is proposed for optimal scheduling in a MG to minimize the COE. The whole proposed algorithm is illustrated in Fig. 1. In this figure, the EMS unit receives power generation data from different generation and storage units at each time step; then it will perform cost optimization on the provided data to calculate the optimal solution for MG operation. The objectives of the proposed EMS include all economic factors and technical constraints of the MG. Since the customer welfare is always the first priority, the main goal of the proposed EMS is defined to supply the total load demand with minimum COE. Therefore, an optimization technique along with an objective function (i.e. cost function in this case) is required. In this study, MILP technique is applied due to the linear objective function and equaility/inequality constraints. The optimization problem is then defined based on the COE from different generation assets and storage devices, given by:

Subject to:

$$
\sum_{1}^{24}\left(\begin{array}{c}
\mathbf{P}_{t}^{\mathrm{WT}} \times \pi^{\mathrm{WT}} \\
+\mathbf{P}_{\mathbf{t}}^{\mathrm{PV}} \times \pi^{\mathrm{PV}} \\
+\mathbf{P}_{\mathbf{t}}^{\mathrm{MT}} \times \pi^{\mathrm{MT}} \\
+\mathbf{P}_{\mathbf{t}}^{\mathrm{ES}-} \times \pi^{\mathrm{ES}-} \\
-\mathbf{P}_{\mathbf{t}}^{\mathrm{ES}+} \times \pi^{\mathrm{ES}+} \\
-\mathbf{P}_{\mathbf{t}}^{\mathrm{EWH}} \times \pi^{\mathrm{EWH}} \\
+\mathbf{P}_{\mathbf{t}}^{\mathrm{UP}} \times \pi^{\mathrm{UP}}
\end{array}\right) \times \Delta t
$$

- Power balance

$$
\mathbf{P}_{t}^{\mathrm{WT}}+\mathbf{P}_{t}^{\mathrm{PV}}+\mathbf{P}_{t}^{\mathrm{ES}-}+\mathbf{P}_{t}^{\mathrm{MT}}+\mathbf{P}_{t}^{\mathrm{UP}}=\mathbf{P}_{t}^{\mathrm{n}}+\mathbf{P}_{t}^{\mathrm{ES}+}+\mathbf{P}_{t}^{\mathrm{EWH}}(7)
$$

- Maximum/minimum renewable generation unit

$$
\begin{aligned}
& \underline{\mathbf{P}}^{\mathbf{W T}} \leq \mathbf{P}_{\mathbf{t}}^{\mathbf{W T}} \leq \overline{\mathbf{P}}^{\mathbf{W T}(8)} \\
& \underline{\mathbf{P}}^{\mathbf{P V}} \leq \mathbf{P}_{\mathbf{t}}^{\mathbf{P V}} \leq \overline{\mathbf{P}}^{\mathbf{P V}(9)}
\end{aligned}
$$

- Spinning reserve [2]

$$
\begin{array}{r}
{\left[D T_{t-1}^{i}-\mathrm{T}^{\mathrm{ON}, i}\right] \cdot\left[X_{t-1}^{i}-X_{t}^{i}\right] \geq 0, \forall i, t(10)} \\
{\left[-D T_{t-1}^{i}-\mathrm{T}^{\mathrm{OFF}, i}\right] \cdot\left[X_{t}^{i}-X_{t-1}^{i}\right] \geq 0, \forall i, t} \\
\mathrm{P}_{\mathrm{t}}^{\mathrm{g}_{\mathrm{i}}}-\mathrm{P}_{\mathrm{t}-1}^{\mathrm{g}_{\mathrm{i}}} \leq \overline{\mathrm{R}}^{\mathrm{i}} \\
P_{t-1}^{g_{i}}-P_{t}^{g_{i}} \leq \underline{R}^{i}(12)
\end{array}
$$

where: $\boldsymbol{D T} \boldsymbol{T}_{\boldsymbol{t}}^{i}$ is a time period which unit $\mathrm{i}$ can be turned on at time $\mathrm{t}, \mathbf{T}^{\mathbf{O N}, i}$ is minimum up-time of unit I (hours),

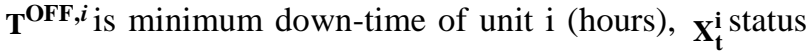
of unit $i$ at each time $t$ (i.e. $\mathbf{X}_{\mathbf{t}}^{\mathbf{i}}=\mathbf{1}$ when the unit is on, $\mathbf{X}_{\mathbf{t}}^{\mathbf{i}}=\mathbf{0}$ when it is in off state). Also, $\mathrm{P}_{\mathrm{t}}^{\mathrm{gi}}$ is power generated by unit $\mathrm{i}$ at time $\mathrm{t}(\mathrm{kW}), \overline{\boldsymbol{R}}^{i}$ is maximum generation level of unit $\mathrm{i}(\mathrm{kW})$ and $\boldsymbol{R}^{i}$ is the minimum generation level of unit $\mathrm{i}(\mathrm{kW})$.

- Energy storage [2]

$$
\begin{gathered}
P_{t}^{E S-} \leq \bar{P}^{E S-} \\
P_{t}^{E S+} \leq \bar{P}^{E S+} \\
\underline{E}^{E S} \leq E_{t}^{E S} \leq \bar{E}^{E S}
\end{gathered}
$$

- Controllable loads

\section{The proposed algorithm}

$$
\mathbf{P}_{\mathbf{t}}^{\text {EWH }} \leq \overline{\mathbf{P}}^{\text {EWH }}
$$

Two algorithms named EMS-MILP and MCEMS are investigated in this study. MCEMS development is explained in detail in [2]. EMS-MILP algorithm encompasses the MILP and LEM units as shown in Figure 1.

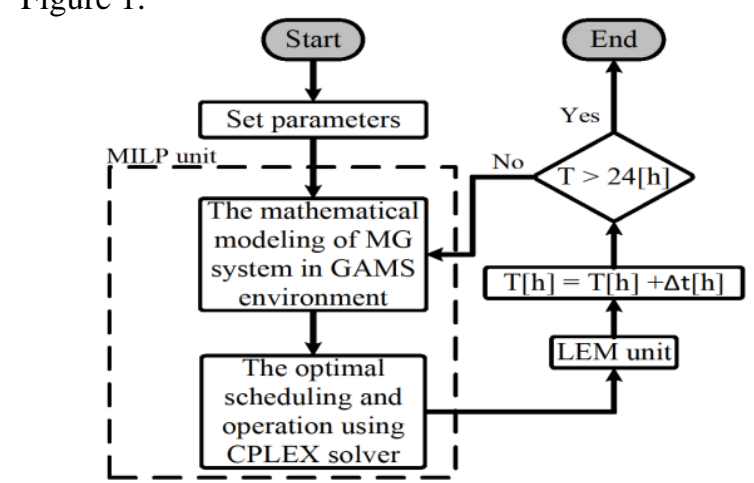

Fig. 1. $\overline{\mathrm{EMS}} \overline{\mathrm{MIL}} \overline{\mathrm{P}}$ algorithm

Each unit are explained in the following sub-sections. 


\section{A. EMS-MILP unit}

The main goals of the EMS-MILP unit are defined as follows:

1- Minimizing the $\mathrm{COE}$ in the MG;

2- Maximizing utilization of the available renewable resources;

3- Maximizing battery lifetime by monitoring and controlling the charge/discharge process;

4- Maximizing the average available stored energy in the battery (i.e., higher battery SOC), hence improving the system reliability;

5- Maximizing utilization of excess available energy from the WT and PV in a useful dump load (i.e., EWHs) when the battery is fully charged in order to increase the system efficiency;

6- Minimizing the amount of UP employing a penalty cost in the Objective Function

\section{B. LEM unit}

The LEM unit in the EMS-MILP algorithm is substantially the same as the one in the MCEMS algorithm. This unit is not explained in this paper; more detailed definition can be found in $[1,2]$.

\section{Application to the test grid}

The single line IREC's MG structure is shown in Fig. 2. The IREC Testbed is also presented in Fig. 3. The details related to the specification of the emulators are presented in Table I [1,2, 24 and 25]. The power profile related to renewable devices (PV and WT in this study) and the power consumed by the non-responsive load (NRL) is also obtained from [1]. The price offer related to the renewable generators, non-renewable generators, non-responsive load and the penalty resulting from UP are mentioned in Table II $[1,2]$.

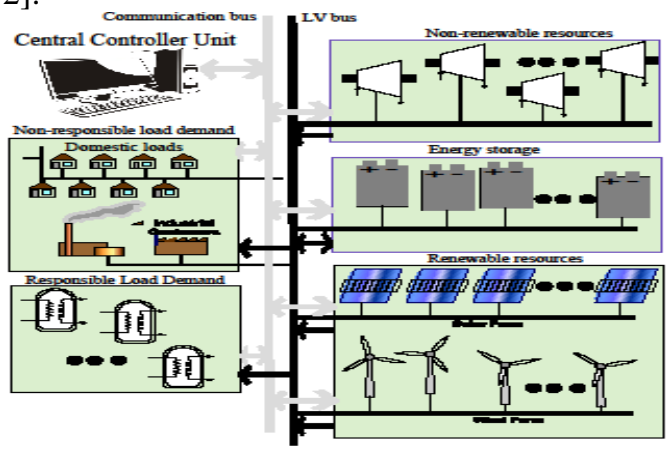

Fig. 2. Schematic of the MG system under study

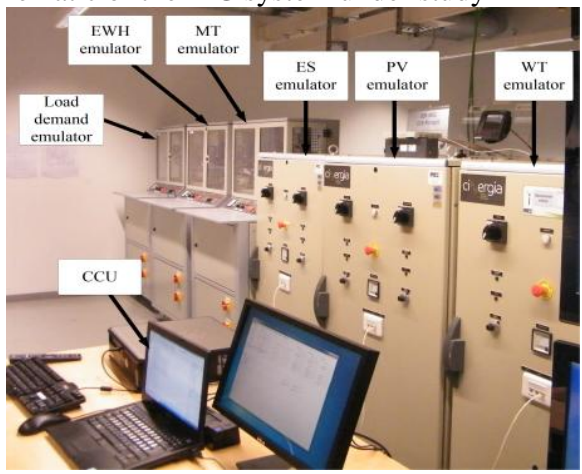

Fig. 3. System configuration of IREC's MG Testbed

Table I. The proposed MG specifications

\begin{tabular}{|c|c|c|}
\hline Parameter & symbol & Value \\
\hline \multicolumn{3}{|c|}{ ES system, Lithum-Ion SYNERION 24M } \\
\hline Voltage (V) & $V_{t}^{E S}$ & 24 \\
\hline Nominal capacity $(\mathrm{Ah})$ at $+25^{\circ} \mathrm{C}$ & $N^{E S}$ & 84 \\
\hline Fully Charged voltage (V) & $V_{\text {Float }}$ & 26 \\
\hline Cut-Off discharge voltage (V) & $V_{\text {Cutoff }}$ & 21 \\
\hline $\begin{array}{l}\text { The maximum of continuous charge } \\
\text { current (A) }\end{array}$ & $\bar{I}^{E S+}$ & 34 \\
\hline $\begin{array}{l}\text { The maximum of continuous discharge } \\
\text { current (A) }\end{array}$ & $\overline{I^{E S-}}$ & 160 \\
\hline $\begin{array}{l}\text { The maximum battery power during } \\
\text { charging mode }(\mathrm{kW})\end{array}$ & $\bar{P}^{E S+}$ & 0.816 \\
\hline $\begin{array}{l}\text { The maximum battery power during } \\
\text { discharging mode }(\mathrm{kW})\end{array}$ & $\bar{P}^{E S-}$ & 3.84 \\
\hline $\begin{array}{l}\text { The maximum delivered power by } \\
\text { converter }(\mathrm{kW})\end{array}$ & $\overline{\mathrm{P}}^{\mathrm{ES}}$ & 4 \\
\hline Initial state of charge (SOC) at T (\%) & $\mathrm{SOC}_{I}^{\mathrm{ES}}$ & 50 \\
\hline The maximum SOC $(\%)$ & $\overline{\overline{\mathrm{SOC}}}$ & 80 \\
\hline The minimum SOC $(\%)$ & $\underline{\mathrm{SOC}}$ & 20 \\
\hline $\begin{array}{l}\text { The initial stored energy in the battery } \\
(\mathrm{kW})\end{array}$ & $E_{I}^{E S}$ & 1 \\
\hline $\begin{array}{l}\text { The maximum stored energy in the } \\
\text { battery }(\mathrm{kW})\end{array}$ & $\bar{E}^{E S}$ & 1.600 \\
\hline $\begin{array}{l}\text { The minimum stored energy in the } \\
\text { battery }(\mathrm{kW})\end{array}$ & $\underline{E}^{E S}$ & 0.403 \\
\hline $\begin{array}{l}\text { The maximum capacity of the battery } \\
(\mathrm{kW})\end{array}$ & $E_{T o t}^{E S}$ & 2 \\
\hline The charge efficiency factor $(\%)$ & $\eta_{c}$ & 96 \\
\hline \multicolumn{3}{|l|}{\begin{tabular}{c|c} 
& PV system \\
\end{tabular}} \\
\hline Maximum instantaneous power $(\mathrm{kW})$ & $\overline{\mathrm{P}}^{\mathrm{PV}}$ & 6 \\
\hline Minimum instantaneous power $(\mathrm{kW})$ & $\underline{\mathrm{P}}^{\mathrm{PV}}$ & 0 \\
\hline \multicolumn{3}{|l|}{\begin{tabular}{l|r} 
& WT system \\
\end{tabular}} \\
\hline Maximum instantaneous power $(\mathrm{kW})$ & $\overline{\mathrm{P}}^{\mathrm{WT}}$ & 8 \\
\hline Minimum instantaneous power $(\mathrm{kW})$ & $\underline{\mathrm{P}}^{\mathrm{WT}}$ & 0.45 \\
\hline \multicolumn{3}{|l|}{ MT system } \\
\hline Maximum instantaneous power $(\mathrm{kW})$ & $\overline{\mathrm{P}}^{\mathrm{MT}}$ & 12 \\
\hline Minimum instantaneous power $(\mathrm{kW})$ & $\underline{\mathrm{P}}^{\mathrm{MT}}$ & 0.2 \\
\hline Start-up time of the MT (min) & $\mathrm{T}_{\mathrm{ON}}^{\mathrm{MT}}$ & 10 \\
\hline Shut-down time of the MT (min) & $\mathrm{T}_{\mathrm{OFF}}^{\mathrm{MT}}$ & 10 \\
\hline Ramp down limit $(\mathrm{kW})$ & $\underline{\mathrm{R}}$ & 6 \\
\hline Ramp up limit $(\mathrm{kW})$ & $\overline{\mathrm{R}}$ & 6 \\
\hline \multicolumn{3}{|l|}{\begin{tabular}{|l|l} 
& EWH system \\
\end{tabular}} \\
\hline Maximum EWH power $(\mathrm{kW})$ & $\overline{\bar{P}^{\mathrm{EWH}}}$ & 5 \\
\hline
\end{tabular}

Table II. The supply bids by generation units into a supply curve $[€ / \mathrm{kWh}]$

\begin{tabular}{|c|l|l|l|l|l|l|}
\hline$\pi^{W T}$ & $\pi^{P V}$ & $\pi^{M T}$ & $\pi^{\mathrm{ES}-}$ & $\pi^{\mathrm{ES}+}$ & $\pi^{\mathrm{UP}}$ & $\pi^{\mathrm{EWH}}$ \\
\hline 0.083 & 0.1 & 0.15 & 0.145 & 0.125 & 1.5 & 0.105 \\
\hline
\end{tabular}

\section{Results and discussions}

Simulation studies are carried out for a typical day. Results are provided to study the effect of the auction settlement rules (lowest to highest pricing) as well as the producer's forward commitments on the producer strategic behavior in the LEM. 
Fig. 4 shows the SOC of the battery for both MCEMS and EMS-MILP. The initial battery SOC is assumed to be $\mathrm{SOC}_{\mathrm{I}}$ to better show its charge/discharge pattern. As discussed earlier, the excess available power in the MCEMS will be stored in the battery, however in EMSMILP, this kind of decisions will be made in the objective function based on the minimum COE. In other words, it is more likely to have excess power available from renewable energy units and running MT at the same time in the EMS-MILP.

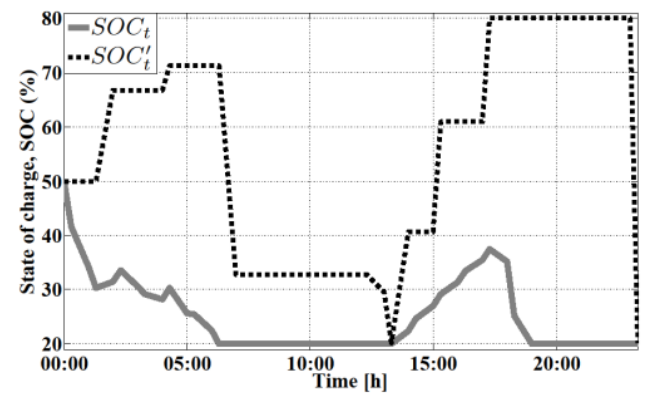

Fig. 4. Battery SOC during one day of simulation

As shown in Fig. 5, the battery maximum charging and discharging power are limited to $\bar{P}^{E S+}$ and $\bar{P}^{E S-}$ to keep battery in the healthy condition to achieve its maximum possible lifetime [3]. In the MCEMS unit, when the total available WT and PV power generation is higher than the total load demand; the excess power will be stored in the battery. Likewise, battery will be discharged only when the WT and PV available power is less than the load demand. In the rest of the time, the battery remains idle in the case of MCEMS algorithm. However, using the MT to meet the load demand might be an option in the case of the EMSMILP if it is cheaper than the battery COE. As seen in this figure, not only the charging period in the EMS-MILP is three hours more than the one in the MCEMS, it also shows less discharging during 24 hours. Therefore, the accumulative energy stored in the battery is higher in the case of the EMS-MILP, which results in a longer battery lifetime and less cost of battery replacement during the lifetime of the project.

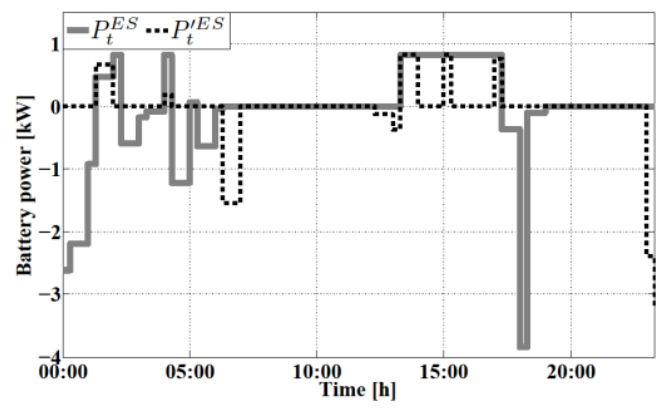

Fig. 5. Battery power for the MCEMS and EMS-MILP in one day simulation

Fig. 6 compares the MT output power profile for the MCEMS and EMS-MILP. In the MCEMS, the MT generates power whenever the available WT, PV and ES are not sufficient to meet the demand or the battery SOC is less than SOC. Therefore, the MT will stay off for the rest of the time. As seen in this figure, both EMSs are following the same pattern during at most of the time. However, the MT operates during some hours in the EMS-
MILP, while the MT is off during the same time in the MCEMS.

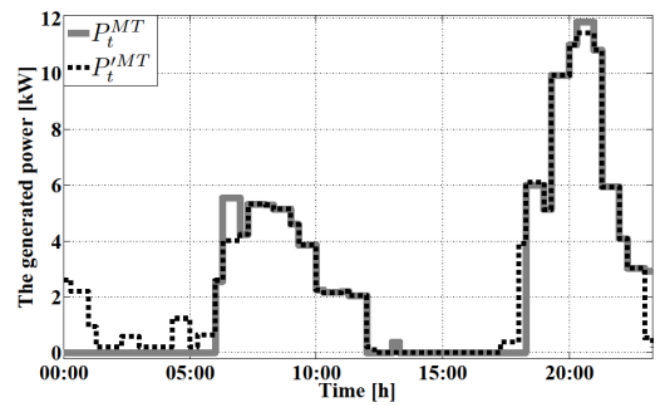

Fig. 6. The hourly MT generated power in the MCEMS and EMS-MILP algorithms during a day of simulation

The market price of the WT is significantly lower than those of the other microsources. Therefore, the WT will be the preferred generation unit with maximum available generation. Fig. 7 illustrates the results of the LEM unit which MCP is computed at each time step for both EMSs. In the MCEMS, the offer from the WT mainly is chosen as the MCP during before the morning. However, the price offer from the WT is also selected as the MCP during in the afternoon. It can be observed that the WT unit (with minimum price offer) in EMS-MILP participates $34 \%$ more in the MCP after midnight until morning and $9 \%$ less in the evening, with respect to the MCEMS.

In both EMSs, the proposed offer by the PV is accepted as the MCP only during morning and evening periods. The percent of PV participation during these periods in the market are around 9\% less and 9\% more than the MCEMS, respectively.

Unlike the PV, ES takes a more significant rule in the market during before morning and in the evening. This percentage for the MCEMS is 50\% more and $8 \%$ less during these periods compared to the EMS-MILP. It is noteworthy to remark that he price offer by the ES is not taken during after midnight until in the morning by the LEM in the EMS-MILP.

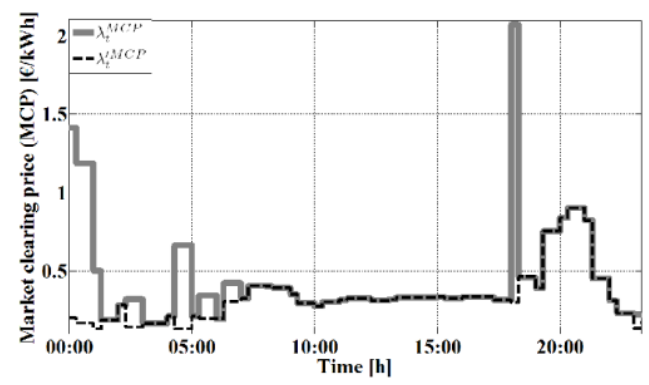

Fig. 7. MCP during 24 hours of simulation for both EMSs

\section{Conclusion}

This paper presents an original EMS for stand-alone MGs incorporating different renewable energy resources and storage units based on two market indicators: single ownership and LEM. The proposed algorithm, in addition to online monitoring, control and optimization of the overall power system performance, could be used to 
optimize energy consumption, most especially during critical periods. Two different EMSs, including the MCEMS and the EMS-MILP, have developed and verified in this study. Experimental data obtained from IREC has used to test the performance and accuracy of the proposed EMSs. LEM has also proposed in this paper; to obtain the best purchasing price in a day ahead market, as well as to increase the utilization of the existing distributed energy resources. To compensate for the UP due to unpredictable events in MG during islanded operation mode, DR concept has employed. The performance and accuracy of the proposed algorithm, when tested with real life experimental data obtained from IREC, has really impressive. Simulation results show about $25 \%$ reduction in cost in the EMS-MILP, in comparison with the MCEMS.

\section{Acknowledgement}

The research leading to these results has received funding from the European Union seventh framework program FP7-SMARTCITIES-2013 under grant agreement 608860 (IDE4L) and by the European Regional Development Funds (ERDF, “FEDER Programa Competitivitat de Catalunya 2007-2013").

\section{References}

[1] M. Marzband, A. Sumper, A. Ruiz-Álvarez, J. L. DomínguezGarcía, B. Tomoiag a, Experimental evaluation of a real time energy management system for stand-alone microgrids in dayahead markets, Applied Energy, 106 (0) (2013) 365 - 376.

[2] M. Marzband, A. Sumper, J. L. Domínguez-García, R Gumara-Ferret, Experimental Validation of a Real Time Energy Management System for Microgrids in Islanded Mode Using a Local Day-Ahead Electricity Market and MINLP, Energy Conversion and Management, 76(0) (2013) 314-322.

[3] M. Marzband, A. Sumper, M. Chindris, B. Tomoiaga, Energy management system of hybrid microgrid with energy storage, The International World Energy System Conference (WESC), Suceava, Romania, 2012.

[4] D. Quiggin, S. Cornell, M. Tierney, R. Buswell, A simulation and optimisation study: Towards a decentralised microgrid, using real world fluctuation data, Energy 41 (2012) 549-559.

[5] R. Bayod-Rujula, Future development of the electricity systems with distributed generation, Energy, 34 (3) (2009) 37783.

[6] M. El-Sharkh, A. Rahman, M. Alam, Short term scheduling of multiple grid-parallel PEM fuel cells for microgrid applications, International Journal of Hydrogen Energy, 35 (20) (2010) 11099-106.

[7] X. Guan, Z. Xu, Q. Jia, Energy-efficient buildings facilitated by microgrid, IEEE Transactions on Smart Grid, 1 (3) (2010) 243 -52 .

[8] T. Niknam, F. Golestaneh, A. Malekpour, Probabilistic energy and operation management of a Microgrid containing Wind- Photovoltaic-Fuel cell generation and energy storage devices based on point estimate method and self-adaptive gravitational search algorithm, Energy, 43 (1) (2012) 427-37.

[9] C. Bustos, D. Watts, H. Ren, Microgrid operation and design optimization with synthetic wins and solar resources, IEEE Latin America Transactions, 10 (2) (2012) 1550-62.

[10] T. Niknam, H. Meymand, H. Mojarrad, A practical multiobjective PSO algorithm for optimal operation management of distribution network with regard to fuel cell power plants, Renewable Energy, 36 (2011) 1529-44.

[11] T. Niknam, H. Meymand, H. Mojarrad, An e_cient algorithm for multi-objective optimal operation management of distribution network considering fuel cell power plants, Energy, 36 (1) (2011) 119-32.

[12] S. Obara, S. Watanabe, B. Rengarajan, Operation method study based on the energy balance of an independent microgrid using solar-powered water electrolyzer and an electric heat pump, Energy, 36 (8) (2011) 5200-13.

[13] T. Niknam, H. Z. Meymand, M. Nayeripour, A practical algorithm for optimal operation management of distribution network including fuel cell power plants, Renewable Energy, 35 (8) (2010) 1696-714

[14] H. Morais, P. K_ad_ar, P. Faria, Z. A. Vale, H. M. Khodr, Optimal scheduling of a renewable microgrid in an isolated load area using mixed integer linear programming, Renewable Energy, 35 (2010) 151-6.

[15] K. Agbossou, M. Kolhe, J. Hamelin, T. K. Bose, Performance of a stand-alone renewable energy system based on energy storage as hydrogen, IEEE Transactions on Energy Conversion, 19 (3) (2004) 633-40.

[16] E. R. Sanseverino, M. L. D. Silvestrea, M. G. Ippolitoa, A. D. Paolab, G. L. Reb, An execution, monitoring and replanning approach for optimal energy management in microgrids, Energy, 36 (2011) 3429-36.

[17] I. Maity, S. Rao, Simulation and pricing mechanism analysis of a solar-powered electrical microgrid, IEEE Systems Journal, 4 (3) (2010) 275-84.

[18] I. C. Paschalidis, B. Li, M. C. Caramanis, Demand-side management for regulation service provisioning through internal pricing, IEEE Transactions on Power Systems, 27 (3) (2012) 1531-39.

[19] M. Mohammadi, S. Hosseinian, G. Gharehpetian, Optimization of hybrid solar energy sources/wind turbine systems integrated to utility grids as microgrid under pool/bilateral/hybrid electricity market using PSO, Solar Energy, 86 (2012) 112-25.

[20] A. Pantoja, N. Quijano, A population dynamics approach for the dispatch of distributed generators, IEEE Transactions on Industrial Electronics, 58 (10) (2011) 4559-67.

[21] A. Hawkes, M. Leach, Modelling high level system design and unit commitment for a microgrid, Applied Energy, 86 (2009) 1253-65.

[22] Y. Zoka, A. Sugimoto, N. Yorino, K. Kawahara, J. Kubokawa, An economic evaluation for an autonomous independent network of distributed energy resources, Electric Power Systems Research, 77 (2007) 831-38.

[23] A. Drud, Conop[Online]. Available:

http://www.gams.com/dd/docs/solvers/conopt.pdf [accessed July 31 2012].

[24] A. Ruiz-Alvarez, A. Colet-Subirachs, F. Alvarez Cuevas Figuerola, O. Gomis-Bellmunt, A. Sudriia-Andreu, Operation of a utility connected microgrid using an IEC 61850 based multi-level management system, IEEE Transactions on Smart Grid, 3 (2) (2012) 858-65.

[25] A. Colet-Subirachs, A. Ruiz-Alvarez, O. Gomis-Bellmunt, F. Alvarez-Cuevas-Figuerola, A. Sudria-Andreu, Centralized and distributed active and reactive power control of a utility connected microgrid using IEC 61850, IEEE Systems Journal, 6 (1) (2012) 58-67. 